\title{
A Novel Dual-Band “C+O” Structure Antenna
}

\author{
Tangyao Xie $\mathbb{D}$, ${ }^{1}$ Jianguo Yu $\mathbb{D},{ }^{1}$ Ziheng Lin $\mathbb{D},{ }^{2}$ Yao $\mathrm{Li}\left(\mathbb{D},{ }^{2}\right.$ Guodong Zhang $\mathbb{D},{ }^{2}$ \\ and Zhen $\mathbf{Y u} \mathbb{D i D}^{2}$
}

${ }^{1}$ Beijing University of Posts and Telecommunications, Beijing, China

${ }^{2}$ North China Institute of Science and Technology, Beijing, China

Correspondence should be addressed to Zhen Yu; yzyuzhen@ncist.edu.cn

Received 22 September 2021; Revised 4 November 2021; Accepted 8 November 2021; Published 24 November 2021

Academic Editor: Ahmed Toaha Mobashsher

Copyright $\odot 2021$ Tangyao Xie et al. This is an open access article distributed under the Creative Commons Attribution License, which permits unrestricted use, distribution, and reproduction in any medium, provided the original work is properly cited.

\begin{abstract}
This article proposes a novel multiband antenna with " $\mathrm{C}+\mathrm{O}$ " structure, which uses two classic circular letters and combines them. The antenna is suitable for wireless applications such as second generation (2G), third generation (3G), fourth generation (4G), WLAN, and Bluetooth. The antenna is based on the structural characteristics of the classic monopole antenna. It is a vertical quarter-wavelength antenna. The radiator of the antenna is mainly composed of letters, and the radiator is symmetrical along the feeder line. The antenna radiator is composed of " $\mathrm{C}+\mathrm{O}$ " structure. The antenna uses a coplanar waveguide feeding method. After actual testing, the antenna covers two frequency bands: $1.82-2.66 \mathrm{GHz}$ and $3.46-3.72 \mathrm{GHz}$. The center frequency points are $2.06 \mathrm{GHz}$ and $3.68 \mathrm{GHz}$. The antenna uses FR-4 dielectric material, the relative dielectric constant of the dielectric plate is 4.4, and the actual size of the antenna is $15 \times 15 \times 1.6 \mathrm{~mm}^{3}$. The test and simulation have good consistency, which verifies that the proposed antenna meets the requirements of various wireless applications.
\end{abstract}

\section{Introduction}

With the rapid development of wireless mobile devices and the wide application of array antennas, miniaturization and ultrathinness of antennas have become a development trend in recent years. The requirements for miniaturization, multifrequency bands, low cost, and easy integration and loading of the unit antennas in the array are becoming higher and higher. Traditional antennas are difficult to be widely used in arrays and mobile terminals due to the limitations of self-generation [1]. The miniaturization and multifunctionalization of the current communication equipment requires the built-in antenna to have strong integration capabilities and multiband characteristics [2, 3]. The array antenna also needs to meet these requirements $[4,5]$.

In recent years, in order to meet the requirements of multiple frequency bands and miniaturization, antenna design can go through multiple iterations to improve its performance. For example, an antenna design similar to the fractal iteration of Chinese classical coins fills up the space through multiple iterations of square and circle, changing the characteristics of current and radiation, so as to obtain good return loss and antenna efficiency [6]. There is also a Koch snowflake fractal to realize the multiband of the antenna [7, 8]. The multifrequency band of the antenna can also be realized by adding branches of the radiator. The effect of increasing the current path is achieved by increasing the branches of the radiator. For example, the banana leaf structure antenna uses leaf veins as the radiator to make the current flow through different leaf veins to achieve multifrequency effects [9]. Two Y-shaped strips are coupled to each other to obtain dual frequency bands. The upward Y-shaped strip provides $3.56 \mathrm{GHz}$, and the downward Y-shaped strip provides $4.63 \mathrm{GHz}$. The antenna in the literature covers the two frequency bands of WLAN and WiMAX as a whole [10]. There was an ultra-wideband antenna that can use formulas to plan the upper and lower lobes of the blade and then scale it down for fractal iteration [11]. The antenna in this article is implemented by introducing a hexagonal open resonant ring into the radiation element to achieve three frequency bands. Each frequency band can be of independent control [12]. The resonant frequency of each frequency band can be controlled by 
changing the length of the antenna radiator branch, and formula (1) can be used to extract the specific length of the antenna $[13,14]$.

$$
l=\frac{c}{4 f_{0} \sqrt{\varepsilon_{e f f}}} .
$$

In addition to adding branches of the antenna radiator to increase current flow, the antenna can also add a slot in the radiator to increase the current path. The antenna radiator is grooved with reference to the classical Chinese reciprocal pattern structure, and the required frequency band is obtained by calculating the length and width of the groove [15]. The local current mode is changed on the antenna radiator to produce different resonant frequencies [16]. It can be understood from this article that the tapered structure can effectively increase the bandwidth and improve the impedance matching of the antenna and the antenna can be cut in half to achieve miniaturization [17]. Not only that, there are many ways to achieve multiband antennas, including coupling feed technology [18-21], matching network technology $[22,23]$, and distributed inductive loading technology $[24,25]$.

At present, the research on new antenna technology has been initially mature at home and abroad. According to the mutual combination of letters to form a complex and changeable structure, it has important research value for the design and realization of multiband and miniaturized antennas. This article combines " $\mathrm{C}$ " and "O," which greatly reduces the overall size of the antenna. The size of the antenna is $15 * 15 * 1.6 \mathrm{~mm}^{3}$, which can be used for multiband mobile terminals. The antenna covers several commercial frequency bands: TD-SCDMA (1,880-2,025 MHz), WCDMA (1,920-2,170 MHz), CDMA2000 (1,920-2,125 MHz), LTE33-41 (1.9-2.69 GHz), Bluetooth (2,400-2,483.5 MHz), GPS (L1, L4), BDS (B1), GLONSS (L1), GALILEO (E1, E2), WLAN $(802.11 \mathrm{~b} / \mathrm{g} / n$ : $2.4-2.48 \mathrm{GHz}), \quad(802.11 \mathrm{a} / n: \quad 5.15-5.35 \mathrm{GHz}), \quad \mathrm{LTE} 42 / 43$ (3.4-3.8 GHz), and WiMAX $(3.3-3.8 \mathrm{GHz})$ systems.

\section{Antenna Structure and Design Procedure}

2.1. Characteristics of the Antenna Structure. The length and width of the radiator are calculated according to well-known mathematical equations:

$$
f=\frac{c}{2 L \sqrt{\varepsilon_{r}}}
$$

where $L$ is the length of the antenna radiator, $f$ is the center frequency of the antenna during operation, $c$ is the speed of light in free space $\left(3 \times 10^{8} \mathrm{~m} / \mathrm{s}\right)$, and $\varepsilon r$ is the dielectric constant of the dielectric plate.

The structure and parameters of the antenna are shown in Figure 1, and the size table is shown in Table 1. The antenna is inspired by the Latin letters " $\mathrm{C}$ " and "O," and the radiator is transformed into a monopole antenna formed by nesting and combining two letters. The feed line of $50 \Omega$ resistance is connected to the rectangular ground, and the feed mode of the coplanar waveguide is adopted. The

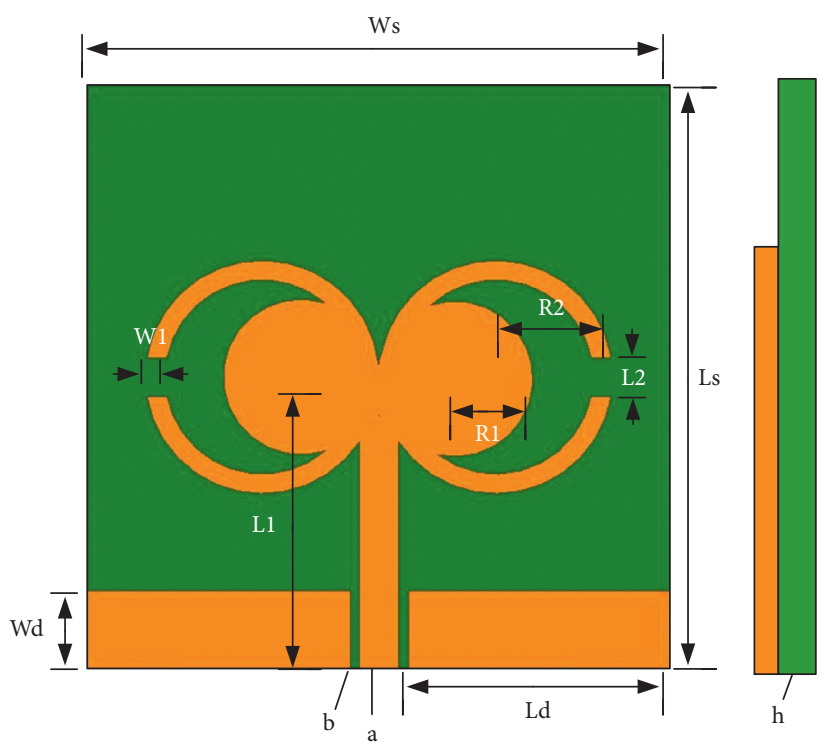

Figure 1: "C + O" structure antenna model.

TABle 1: Antenna parameters.

\begin{tabular}{lcccccc}
\hline Size parameters & Ws & Ls & Wd & Ld & W1 & L1 \\
\hline unit $(\mathrm{mm})$ & 30 & 30 & 4 & 13.5 & 1.017 & 15 \\
Size parameters & L2 & R1 & R2 & a & b & h \\
unit $(\mathrm{mm})$ & 2 & 4 & 6 & 2 & 0.5 & 1.6 \\
\hline
\end{tabular}

antenna adopts the substrate FR-4 material, the thickness is $1.6 \mathrm{~mm}$, the relative dielectric constant is 4.4 , and the loss tangent is 0.02 .

\section{Results and Discussion}

3.1. Simulation Results. The simulation was performed using the Ansoft High-Frequency Simulation Software (HFSS) (version 18.0). Figure 2(a) illustrates a monopole antenna with a symmetrical " $C$ " letter structure. The antenna produces one frequency band, namely, 2.1 GHz. Figure 2(a) shows a symmetrical monopole antenna. The antenna radiation pattern consists of the Latin letter "O." The antenna generates two frequency bands, namely, 2.3 and $3.58 \mathrm{GHz}$. The abovementioned four parameters were optimised and analysed in order to obtain an antenna return loss performance suitable for the applicable ranges of GPS, WLAN, LTE, and other commercial frequency bands.

As shown in Figure 3, the proposed antenna can work in two different frequency bands; the center frequency points are 2.3 and $3.58 \mathrm{GHz}$, and the corresponding return losses are -19.1 and $-27.5 \mathrm{~dB}$. The simulated $-10 \mathrm{~dB}$ return loss bandwidth is $35 \%$ for the first frequency band $(1.81-2.75 \mathrm{GHz})$ and $6 \%$ for the last band $(3.48-3.78 \mathrm{GHz})$. These frequency bands cover the commercial frequency bands, such as GPS, WLAN, LTE, WiMAX, Bluetooth, and satellite communications (see Table 2).

The surface current distribution diagram and current vector distribution diagram of the antenna radiator at the center frequencies of 2.3 and $3.58 \mathrm{GHz}$ are shown in 

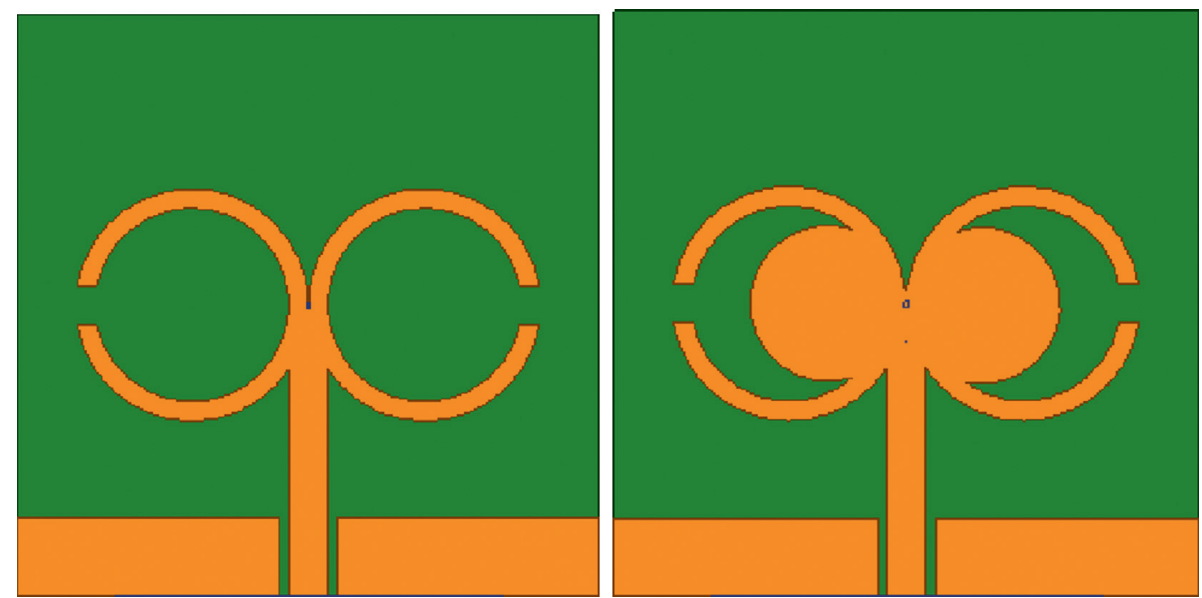

Figure 2: “C $+\mathrm{O}$ ” model evolution process diagram.

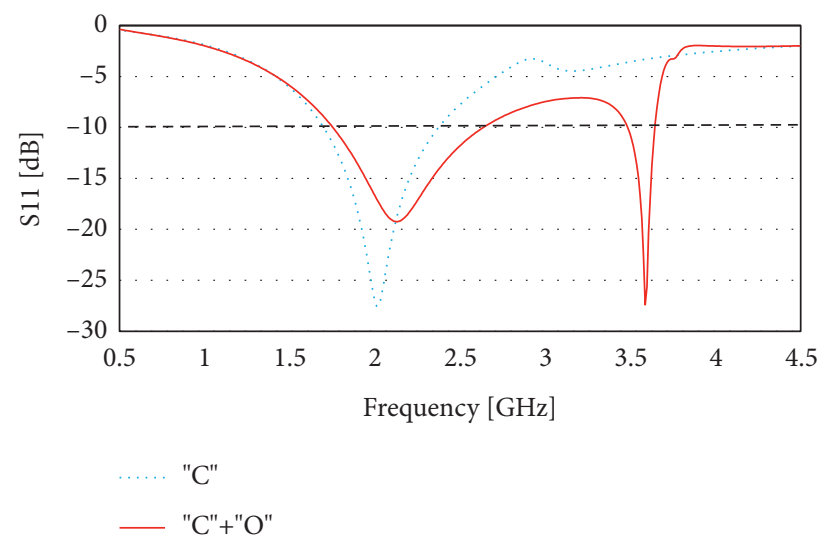

Figure 3: Combined simulated return loss for antenna evolutions.

TABLE 2: Measured and simulated frequency band comparison of the antenna.

\begin{tabular}{cccc}
\hline & Simulation & Measurement & Coverage frequency band \\
\hline \multirow{2}{*}{1} & $1.81-2.75 \mathrm{GHz}$ & $1.82-2.66 \mathrm{GHz}$ & TD-SCDMA (1,880-2,025 MHz), WCDMA (1,920-2,170 MHz), CDMA2000 \\
& $(42.7 \%)$ & $(40.8 \%)$ & $(1,920-2,125 \mathrm{MHz}), \mathrm{LTE} 33-41(1.9-2.69 \mathrm{GHz})$, Bluetooth $(2,400-2,483.5 \mathrm{MHz}), \mathrm{GPS}(\mathrm{L} 1$, \\
2 & $3.48-3.78 \mathrm{GHz}$ & $3.46-3.72 \mathrm{GHz}$ & $\mathrm{L} 4), \mathrm{BDS}(\mathrm{B} 1), \mathrm{GLONSS}(\mathrm{L} 1)$, GALILEO (E1, E2), WLAN (802.11 b/g/n: $2.4-2.48 \mathrm{GHz})$, \\
& $(8.3 \%)$ & $(7.1 \%)$ & $(802.11 \mathrm{a} / n: 5.15-5.35 \mathrm{GHz}), \mathrm{LTE} 42 / 43(3.4-3.8 \mathrm{GHz})$, and WiMAX $(3.3-3.8 \mathrm{GHz})$ \\
\hline
\end{tabular}

Figures 4(a)-4(b). When the antenna is working at $2.3 \mathrm{GHz}$, the antenna current is mainly distributed in the lower half of "C" and a small part of the current is concentrated in the upper half. When the antenna works at $3.58 \mathrm{GHz}$, the current of the antenna is mainly concentrated on the entire "C" structure. Therefore, the length of the radiator that caused the first resonance can be calculated as

$$
L_{a} \approx \frac{2 \pi R_{2}}{2}+\frac{2 \pi R_{2}}{3}=31.4 \mathrm{~mm}
$$

According to the data in Table $1, L=10 \mathrm{~mm}$ can be obtained, which can be used to calculate the frequency band corresponding to this length:

$$
f_{a}=\frac{c}{2 L_{a} \sqrt{\varepsilon_{r}}} \approx 2.285 \mathrm{GHz}
$$

It can be seen from Figure 4(b) that when the antenna is at $3.58 \mathrm{GHz}$, the current is mainly concentrated on the outer ring, which can verify the correspondence between the length of the antenna radiator and the antenna resonance point:

$$
\begin{aligned}
& L_{b} \approx 2 \pi R_{2}-4 L_{2}-\frac{2 \pi R_{2}}{5}=22.01 \mathrm{~mm} \\
& f_{b}=\frac{c}{2 L_{b} \sqrt{\varepsilon_{r}}} \approx 3.26 \mathrm{GHz}
\end{aligned}
$$

The $3 \mathrm{D}$ radiation pattern of the antenna and the cross polarization in the E/H-plane are shown in Figures 5 and 6. The $3 \mathrm{D}$ gain graph and the cross polarization in the $\mathrm{E} / \mathrm{H}$ plane obtained by the simulation are shown in Figures 5 and 6 . The blue dashed line represents the main polarization 

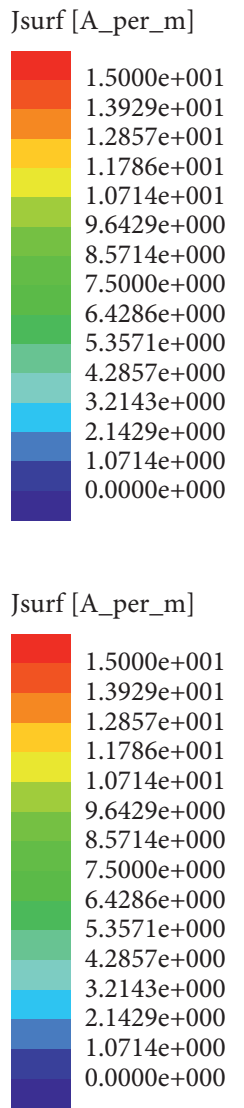
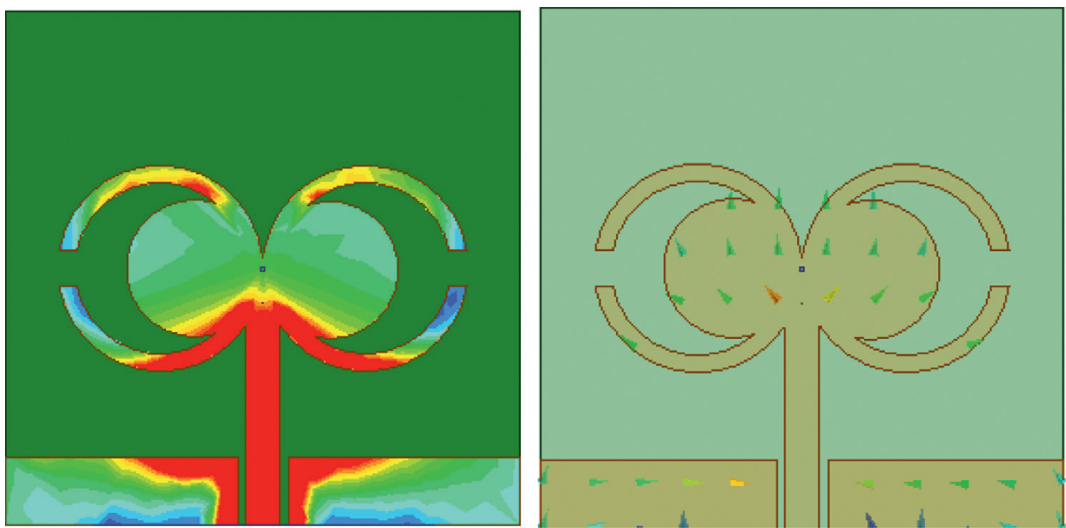

(a)
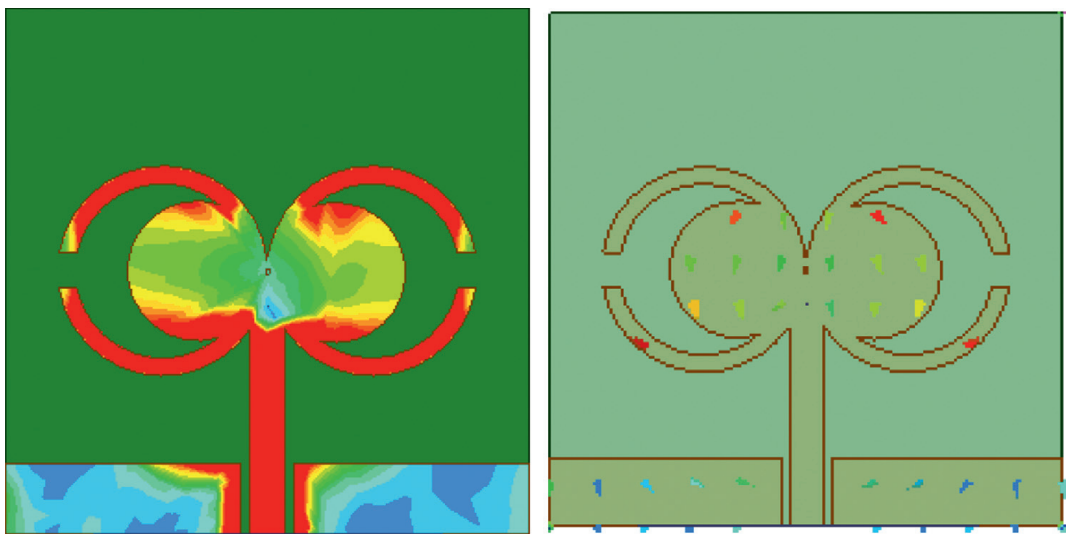

(b)

FIgURE 4: Current amplitude and vector distribution of the antenna. (a) $2.3 \mathrm{GHz}$. (b) $3.58 \mathrm{GHz}$.
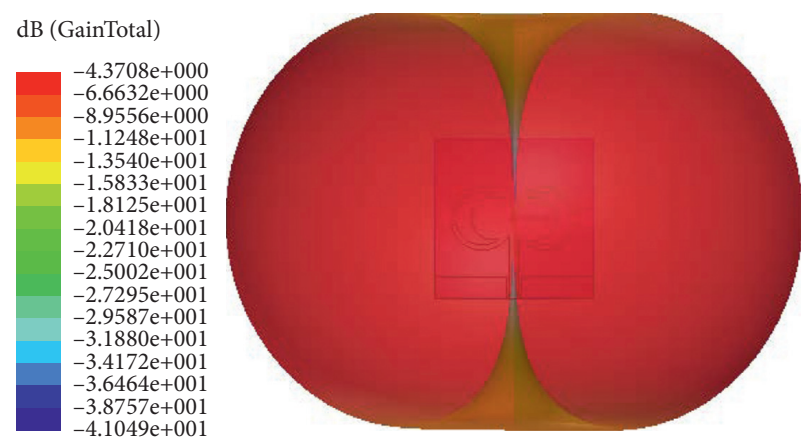

(a)

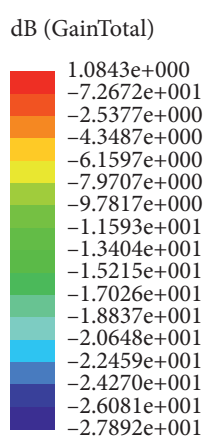

$-2.7892 \mathrm{e}+001$

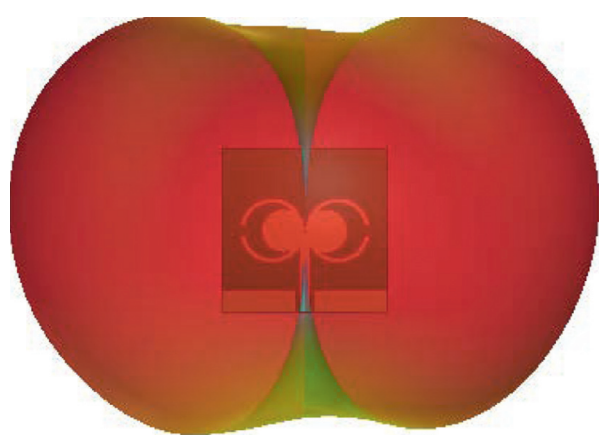

(b)

FIGURE 5: 3D radiation patterns. (a) $2.3 \mathrm{GHz}$. (b) $3.58 \mathrm{GHz}$.

when Phi $=90^{\circ}$, and the blue solid line represents the cross polarization when $\mathrm{Phi}=90^{\circ}$. The red solid line represents the main polarization when $\mathrm{Phi}=0^{\circ}$, and the red dashed line represents the cross polarization when $\mathrm{Phi}=0^{\circ}$. At the center frequencies of $2.3 \mathrm{GHz}$ and $3.58 \mathrm{GHz}$, the antenna gains are $-4.37 \mathrm{dBi}$ and $1.04 \mathrm{dBi}$, respectively. It can be clearly seen that the antenna maintains a good radiation characteristic in the available frequency band, the omnidirectionality of the $\mathrm{E}$ plane and the $\mathrm{H}$ plane is good, and there is almost no zero point. The antenna has a small cross polarization characteristic.
3.2. Fabrication and Measurement Results. The antenna is designed on an FR-4 substrate with a thickness of $1.6 \mathrm{~mm}$ and loss tangent of 0.02 , and a $30 \mu \mathrm{m}$ thick copper layer is engraved on both sides. A prototype was manufactured and measured, and the measurement was performed in a microwave anechoic chamber with a shielding effect of $100 \mathrm{MHz}-9 \mathrm{GHz} \geq 100 \mathrm{~dB}$ at $6000 \times 3200 \times 3200 \mathrm{~mm}$ to verify the broadband performance of the multifrequency planar antenna. The measured and simulated antenna is located at the $-10 \mathrm{~dB}$ return loss band, as shown in Figure 7. The antenna's return loss frequency band at $-10 \mathrm{~dB}$ has two frequency bands: $1.82-2.66 \mathrm{GHz}(40.8 \%)$ and 


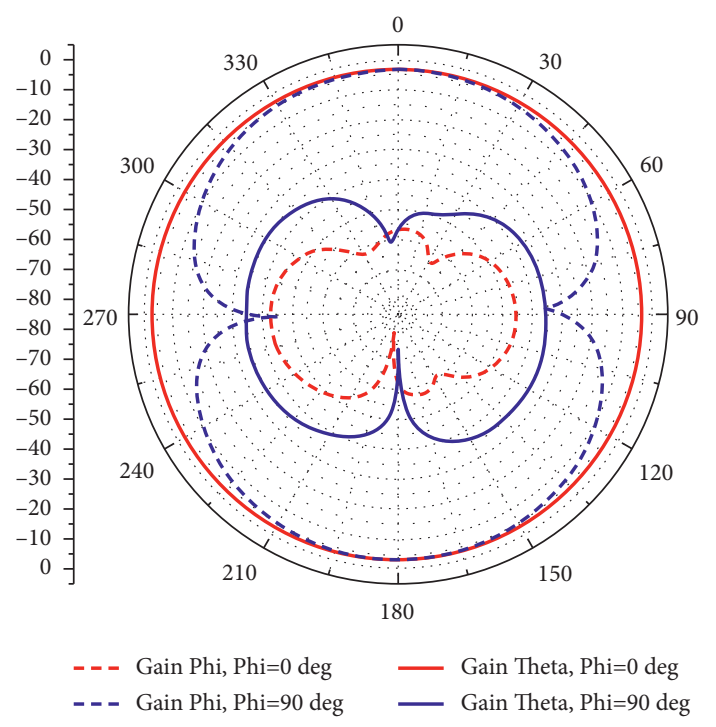

(a)

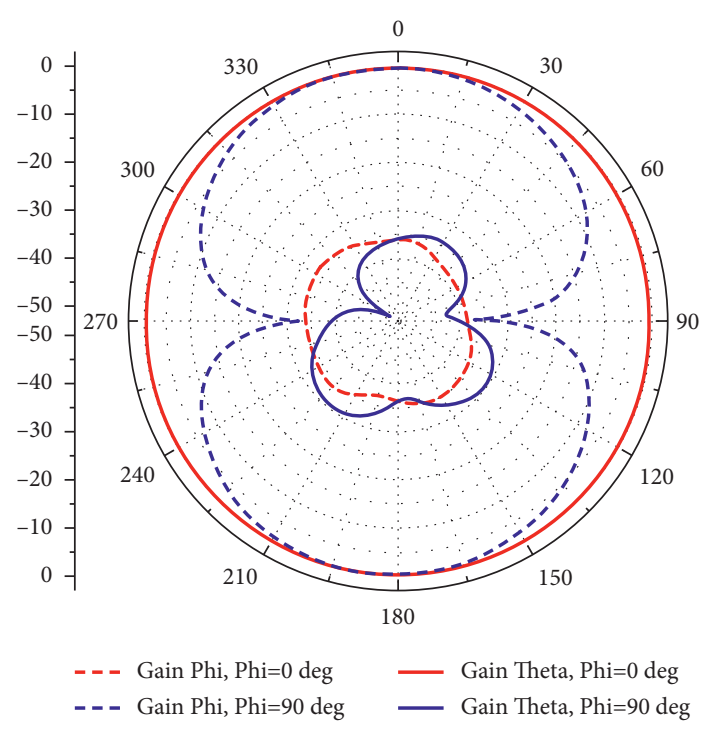

(b)

Figure 6: E/H-plane radiation patterns. (a) $2.3 \mathrm{GHz}$. (b) $3.58 \mathrm{GHz}$.

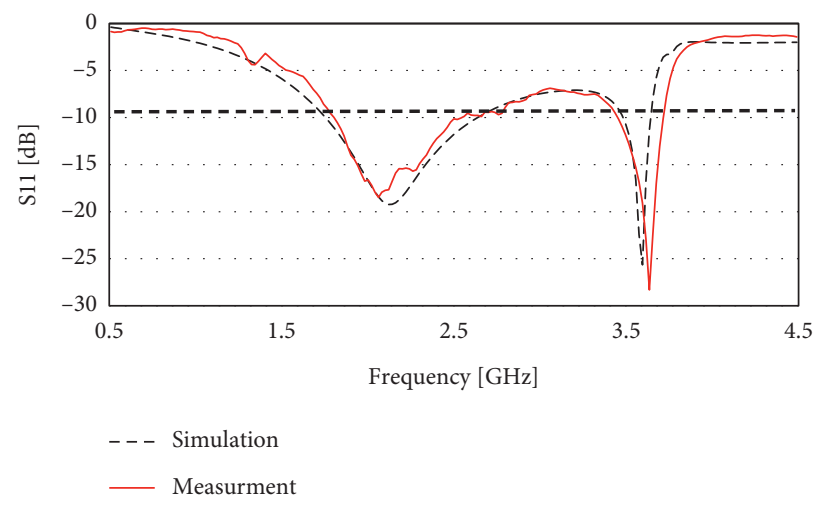

Figure 7: Measurement and simulation S11 of the antenna.

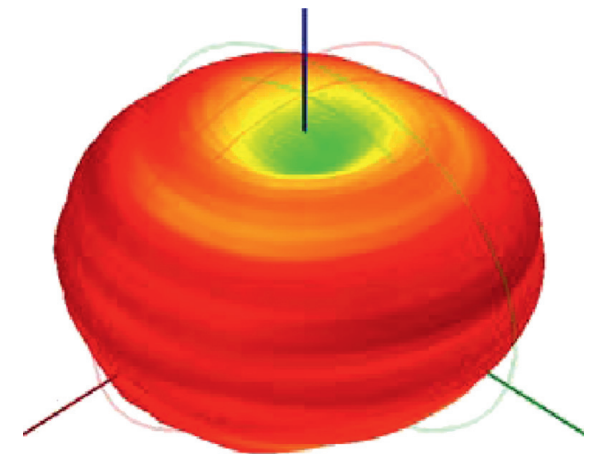

(a)

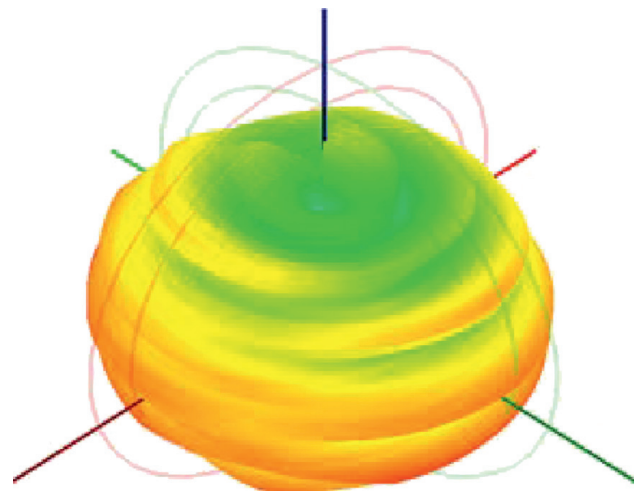

(b)

Figure 8: Measurement 3D radiation pattern of the antenna. (a) $2.3 \mathrm{GHz}$. (b) $3.58 \mathrm{GHz}$.

3.46-3.72 GHz (7.1\%). The generated frequency band can cover $2 \mathrm{G}, 3 \mathrm{G}$, and $4 \mathrm{G}$ mobile communication systems, as well as wireless applications, such as Bluetooth and satellite navigation. The bandwidth of $-10 \mathrm{~dB}$ return loss is roughly identical to the simulation frequency band, as shown in Table 2 . Comparing the antenna test and simulation results, the actual test results cover more frequency bands and have a wider bandwidth. The return loss performance is in good agreement. 

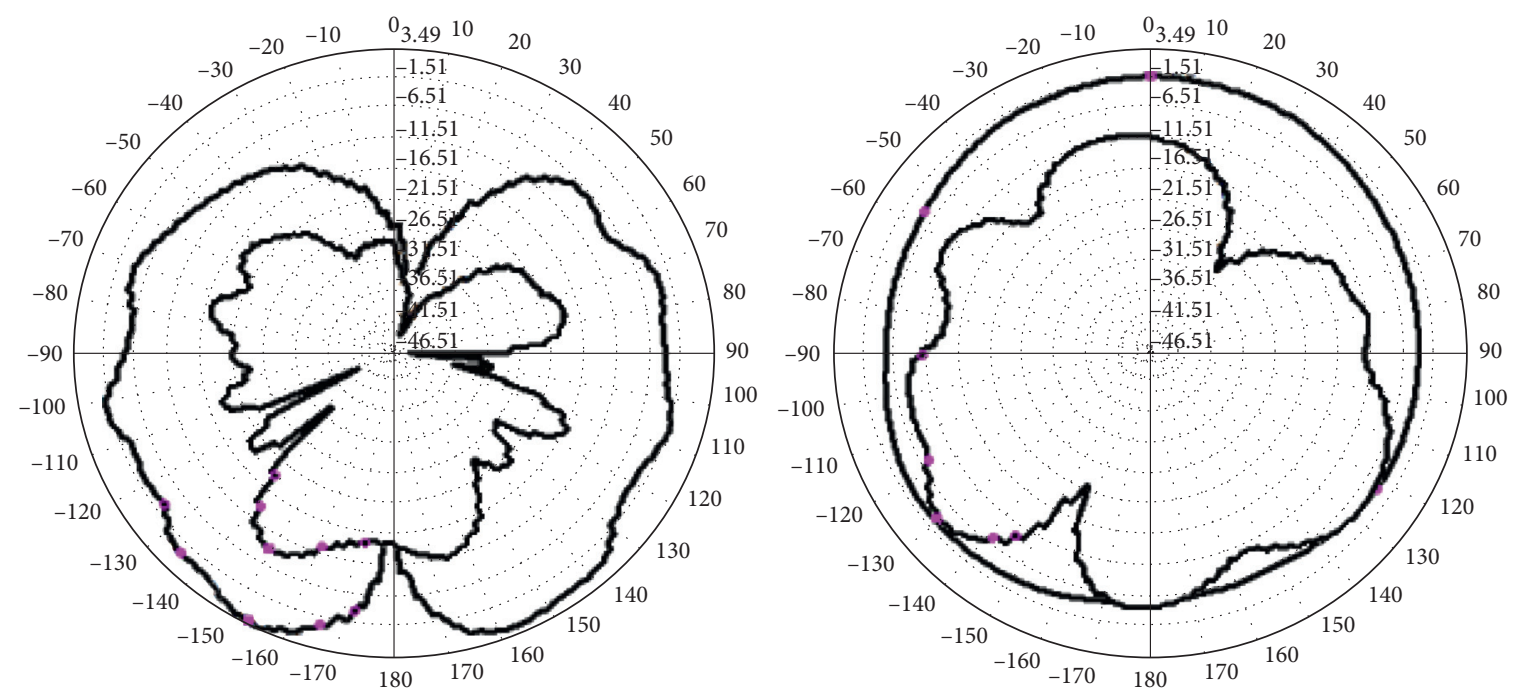

(a)
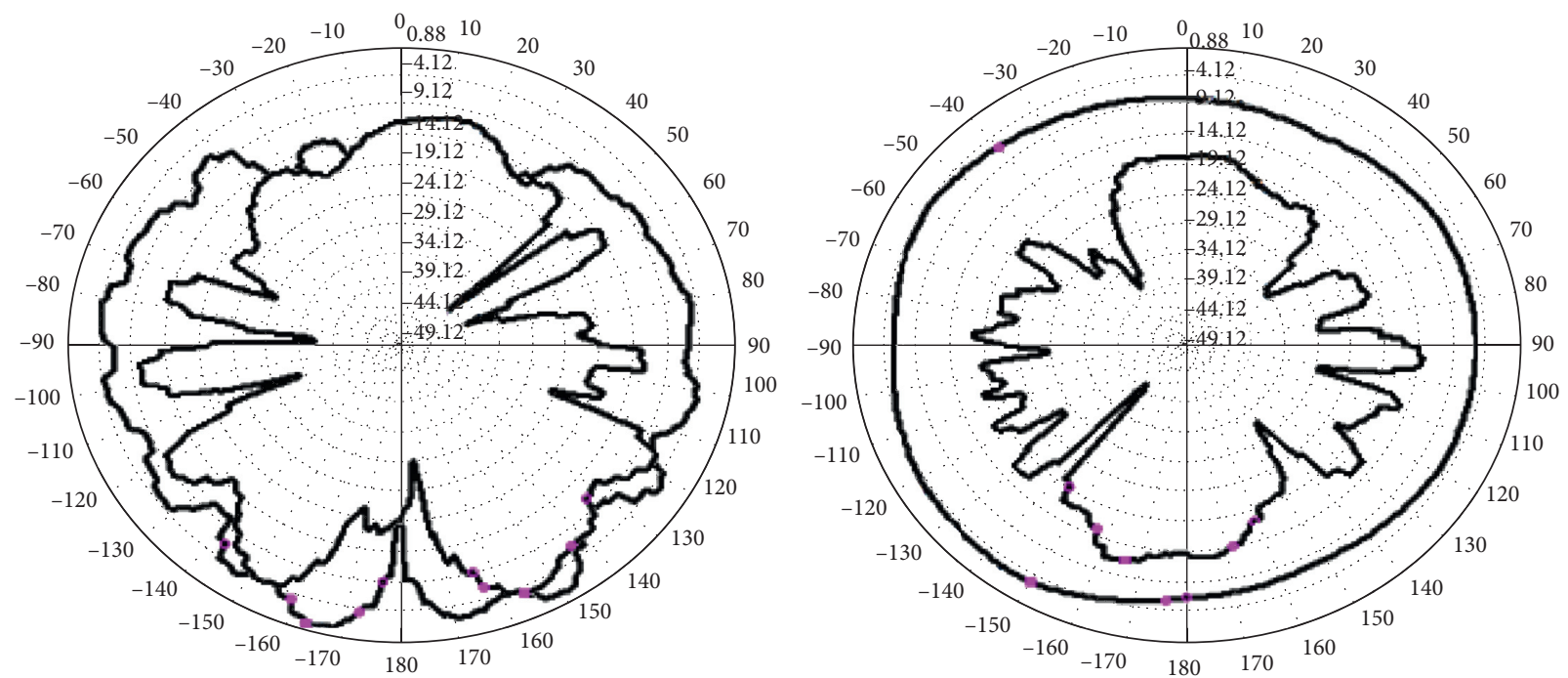

(b)

Figure 9: E/H-plane radiation patterns. (a) $2.3 \mathrm{GHz}$. (b) $3.58 \mathrm{GHz}$.

Figures 8 and 9 show the measured 3D radiation pattern and the radiation pattern of the $\mathrm{E} / \mathrm{H}$-plane when the antenna is at $2.3 \mathrm{GHz}$ and $3.58 \mathrm{GHz}$. It can be obtained by comparison with simulation data that the antenna has good omnidirectional radiation. As the frequency increases, the side lobes of the antenna gradually appear, but there is no zero point. Due to the manufacturing accuracy, dielectric material, and environmental elements in the antenna manufacturing process, there are still some errors. The final test results are in good agreement with the simulation data. The gain and efficiency of the antenna tested at $0.5-4.5 \mathrm{GHz}$ are shown in Figure 10. The gain of the antenna in the usable frequency band of $1.78-3.80 \mathrm{GHz}$ varies between 1.1 and $4.81 \mathrm{dBi}$, and the efficiency varies around $49 \%$.

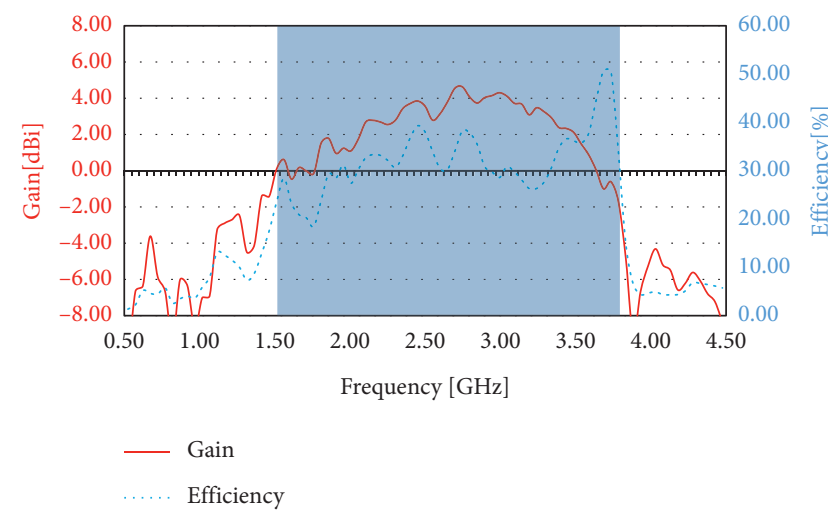

Figure 10: Measured gain and efficiency curves. 


\section{Conclusions}

In this article, a small multiband antenna with a classic letter structure is developed, the size of which is only $15 \times 15 \times 1.6 \mathrm{~mm}^{3}$. The final frequency band and bandwidth of the antenna are $1.82-2.66 \mathrm{GHz} \quad(40.8 \%)$ and $3.46-3.72 \mathrm{GHz}$ (7.1\%). This covers multiple commercial frequency bands such as DCS, WLAN, Bluetooth, and LTE. The radiation direction of the antenna is omnidirectional, and the simulation and actual measurement have good consistency, which verifies the good radiation characteristics of the antenna. Because the antenna is small in size and light in weight, it can make some reference for the research of the element antenna in the array antenna.

\section{Data Availability}

The data used to support the findings of this study are included within the article.

\section{Conflicts of Interest}

The authors declare that they have no conflicts of interest.

\section{Acknowledgments}

This work was supported in part by the Natural Science Foundation of Hebei Province (No. F2021508009), Innovative Research Group Project of National Natural Science Foundation of China (No. 61821001), the National Key R\&D Project (No. 2020YFC1511805), the Fundamental Research Funds for the Central Universities under grant 3142018048, and Education and Teaching Reform Special Project of NCIST (Nos. 01010403-55 and 0502010223-16).

\section{References}

[1] S. Verma and P. Kumar, "Compact triple-band antenna for WiMAX and WLAN applications," Electronics Letters, vol. 50, no. 7, pp. 484-486, 2014.

[2] M. Peng, S. Zhang, Y. Cai, X. Q. Lin, and G. F. Pedersen, “A reflectarray antenna designed with gain filtering and low-RCS properties," IEEE Transactions on Antennas and Propagation, vol. 67 , no. 8, 2019.

[3] M. D. Tarikul, I. Mohammad Tariqul, M. D. Samsuzzaman, A. Haslina, and R. Hatem, "Metamaterial loaded nine High gain vivaldi antennas array for microwave breast imaging application," IEEE Access, Digital Object Identifier, vol. 34, Article ID 3045458, 2020.

[4] R. Xu, S. S. Gao, and J.-Y. Li, "Analysis and design of ultrawideband circularly, antenna and array," IEEE Transactions on Antennas and Propagation, vol. 68, no. 12, 2020.

[5] X. ZHANG, L. I. YIXIN, and W. E. I. WANG, "Ultrawideband 8-port MIMO antenna array for 5G metal-frame smartphones," IEEE Access, Digital Object Identifier, vol. 5, Article ID 2919622, 2019.

[6] Z. Yu, J. Yu, X. Ran, and C. Zhu, "A novel ancient coin-like fractal multiband Antenna for wireless applications," International Journal of Antennas and Propagation, vol. 2017, Article ID 6459286, , 2017.

[7] Z. Yu, J. Yu, X. Ran, and C. Zhu, "A novel koch and sierpinski combined fractal antenna for 2G/3G/4G/5G/WLAN/
Navigation applications," Microwave and Optical Technology Letters, vol. 54, 2017.

[8] H. Yang and W. Yang, "An ultra-wideband microstrip antenna based on Koch fractal resonance unit and CSRRs defective ground unit," in Proceedings of the 2020 9th AsiaPacific Conference on Antennas and Propagation (APCAP), Xiamen, China, August 2020.

[9] L. Wang, J. Yu, T. Xie, Z. Yu, B. Liang, and X. Xu, The Design of a Multi-Band Bionic Antenna for Mobile Terminals, Wiley, New York, NY, USA, 2021.

[10] H. Zhai, Q. Gao, Z. Ma, and C. Liang, "Dual Y-shaped monopole antenna for dual-band WLAN/WiMAX operations," International Journal of Antennas and Propagation, vol. 2014, Article ID 481918, 5 pages, 2014.

[11] B. Biswas, R. Ghatak, and D. R. Poddar, "A fern fractal leaf inspired wideband Antipodal vivaldi antenna for microwave imaging system," IEEE Transactions on Antennas and Propagation, vol. 65, no. 11, 2017.

[12] Z. Abir, A. Wahaj Abbas, N. Hussain, and B. Abdennaceur, "A wide and tri-band flexible antennas with independently controllable notch bands for sub-6-GHz communication system," Radioengineering, vol. 29, no. 1, pp. 44-51, 2019.

[13] N. Hussain, A. Abbas, S.-M. Park, S. Gyoon Park, and N. Kim, "A compact tri-band Antenna based on inverted-L stubs for smart devices," Computers, Materials \& Continua, vol. 70, no. 2, pp. 3321-3331, 2022.

[14] A. S. Al-Zayed and V. A. Shameena, "Planar dual-band monopole antenna with an extended ground plane for WLAN applications," International Journal of Antennas and Propagation, vol. 2016, Article ID 6798960, 10 pages, 2016.

[15] Z. Yu, Z. Lin, X. Ran, L. Yao, B. Liang, and X. Wan, “A novel "回” pane structure multiband microstrip antenna for $2 \mathrm{G} / 3 \mathrm{G} /$ 4G/5G/WLAN/Navigation Applications," International Journal of Antennas and Propagation, vol. 2021, Article ID 5567417, 15 pages, 2021.

[16] A. Falahati and M. Naghshvarian-Jahromi, "Dual band-notch cpw-ground-fed uwb antenna by fractal binary tree slot," in Proceedings of the 2009 Fifth International Conference on Wireless and Mobile Communications, La Bocca, France, August 2009.

[17] Y. Cheng, J. Lu, and C. Wang, "Design of a multiple band vehicle-mounted antenna," International Journal of Antennas and Propagation, vol. 2019, Article ID 6098014, 11 pages, 2019.

[18] Y. Chenyin, Y. Shuhui, Y. Chen et al., "A super-wideband and High isolation MIMO antenna system using a windmillshaped decoupling structure," IEEE Access, Digital Object Identifier, vol. 9, Article ID 3004396, 2020.

[19] Z. Zhao, Z. Wei, Z. Tang, and Y. Yin, "Design and analysis of a wideband multiple-microstrip dipole antenna with High isolation," IEEE Antennas and Wireless Propagation Letters, vol. 18, no. 4, 2019.

[20] Z. Yu, Li Yao, Z. Lin, and X. Ran, "Design of window grille shape-based multiband Antenna for mobile terminals," International Journal of Antennas and Propagation, vol. 2021, Article ID 6684959, 14 pages, 2021.

[21] C. Sim and J. H. Zhuang, "A coupled-feed monopole antenna for UHF RFID reader application," in Proceedings of the 2018 International Symposium on Antennas and Propagation (ISAP), Busan, South Korea, October 2018.

[22] D. Qin, B. Sun, and J. Zhang, "A wideband dipole antenna using a impedance-matched network," in Proceedings of the 2018 Cross Strait Quad-Regional Radio Science and Wireless Technology Conference (CSQRWC), Xuzhou, China, July 2018. 
[23] D. Song, H. Xiong, Q. Zhang, Q. Ding, K. Zhang, and M. Huang, "Investigation for transmission characteristic of impedance matching network on short-wave antenna," in Proceedings of the 2013 5th 2013 5th IEEE International Symposium on Microwave, Antenna, Propagation and EMC Technologies for Wireless Communications, Chengdu, China, July 2013.

[24] B. Gong, L. H. Su, Y. Z. Yin, H. Ma, and Q. R. Zheng, "A novel log-periodic dipole antenna with distributed inductive load," in Proceedings of the 2012 2nd International Conference on Consumer Electronics, Communications and Networks (CECNet), Yichang, China, April 2012.

[25] K. Iigusa, T. Sawaya, M. Taromaru, T. Ohira, and B. Komiyama, "Experimental proof of electrically invisible state of inductively loaded dipole and proposal of electrically invisible meander-lines," IEEE Transactions on Antennas and Propagation, vol. 54, no. 11, 2006. 